\title{
Can Plasma Volume Affect Arterial Stiffness and Autonomic Modulation Response to Resistance Exercise?
}

\author{
Daniel Rodriguez ${ }^{1 *}$, Danilo Bocallini ${ }^{2}$ and Aylton Figueira J $\mathrm{r}^{1}$ \\ ${ }^{1}$ Department of Cardiology, São Judas Tadeu University, Brazil, Nippon Sports Science University, Tokyo, Japan \\ ${ }^{2}$ Espirito Santo Federal University, Espirito Santo, Brazil
}

Submission: July 01, 2019; Published: July 11, 2019

*Corresponding author: Daniel Rodriguez, Department of Cardiology, São Judas Tadeu University, Nippon Sports Science University, Tokyo, Japan

\section{Abstract}

Introduction: Despite the numerous benefits of resistance exercise (RE), stress caused by muscle contractions may cause transient disturbances in the cardiovascular system including arterial stiffness increasing the temporary risk of cardiovascular events. One physiological response which can influence this process but has received little attention from the scientific community is plasma volume (PV).

Discussion: Recent reviews point to a complex interaction between autonomic modulation, central and peripheral adjustments triggered by a RE session. After the end of a moderate to high intensity RE session there may be a reduction in PV caused by its influx into the interstitial tissue and consequent decline in stroke volume and venous return. Moreover, there is an increase in sympathetic modulation, and a decrease in parasympathetic modulation. Arterial stiffness is one of the first signs of pathological changes in the arterial wall leading to an increased risk of cardiovascular events. The stiffening of the main arteries of the body can also be negatively affected by PV reduction. The PV reduction would lead to elevation of sympathetic nerve modulation, cardiac workload and reduction in cardiac perfusion. However, depending of the nature of the $\mathrm{PV}$ reduction contradictory results emerges and decrease in arterial stiffness was also reported.

Conclusion: There is no agreement as to why PV reduction may affect arterial stiffness, and several questions regarding hydration status and RE influence remains to be addressed. Future studies should standardize water intake and control hydration status before and during experimental sessions utilizing simple measures of hydration status.

Keywords: Arterial stiffiness; Plasma volume; Cardiopulmonary; Heart rate

Abbreviations: RE: Resistance Exercise; PV: Plasma Volume; HR: Heart Rate; SNS: Sympathetic Nervous System

\section{Introduction}

It is well established in the literature that the benefits of resistance exercise (RE) for the general physical health of people of all ages go beyond the increase in muscle mass [1]. RE can improve cardiovascular function, reduce risk factors associated with diabetes mellitus, coronary heart disease [2], and high blood pressure [3]. Besides, higher levels of muscle strength are associated with lower risks of mortality [4].

However, despite the numerous benefits of RE, the stress caused by muscle contractions (mainly moderate to high intensity), may cause transient disturbances in the cardiovascular system and arterial stiffness. This response can increase the risk of cardiovascular events such as myocardial infarction and sudden death [5].

In this sense, many of the cardiovascular responses to RE have not been fully elucidated. One physiological response which can influence this relationship but has received little attention from the scientific community is a reduction of plasma volume (PV) [6].

\section{Discussion}

Plasma volume is an important variable, affecting a vast array of physiological functions during exercise, and some studies indicate that changes in its composition may influence cardiovascular system adjustments and autonomic modulation after the exercise.

After the end of a moderate to high intensity RE session, there may be a reduction in plasma volume caused by its influx into the interstitial tissue [7] with a consequent reduction in stroke volume and venous return. This process would result in a deactivation of cardiopulmonary receptors with subsequent increase in heart rate (HR). 
These changes in PV can at least partially explain the behavior of autonomic modulation. Rezk et al. [8] for instance, observed increased HR and stroke volume reduction after high and low intensity RE sessions. According to the authors, reduction in PV was responsible for triggering this response accompanied by an increase in sympathetic modulation, and a decrease in parasympathetic modulation.

In this context, recent reviews point to a complex interaction caused by a RE session between autonomic modulation, central (heart rate and myocardial contractility) and peripheral (i.e., vascular resistance) adjustments [9].

According to Buchheit et al. [10], arterial baroreceptors are dependent on the levels of atrial pressure and stroke volume witch on the other hand is affected by plasma volume. A decrease in plasma volume would exert an inhibitory influence on the receptors of the parasympathetic cardiovascular control centers in the medulla and cause an excitatory effect on the sympathetic nervous system (SNS) with consequent elevation of the HR $[11,12]$.

It is worth mention that during a typical RE session in thermoneutral conditions (temperature 25o C and humidity $50 \%$ ), the loss of fluids due to perspiration/sweat and respiration is considered negligible. The body weight changes caused by dehydration after most RE studies are far less than those observed during aerobic exercise studies [13]. Therefore, the mechanisms for the changes in PV during resistance exercise are not due to loss of body water to the degree as seen with aerobic exercise.

Rodriguez et al. [14] hypothesized that during high intensity $\mathrm{RE}$ the influx of plasma to the active muscle seems to occur due to an imbalance in hydrostatic and osmotic pressure between the capillary terminal and the interstitial tissue of the active muscles. That process can result in an elevated capillary filtration pressure, which facilitates outward filtration of plasma from the intravascular space into the surrounding tissues [15] resulting in reduction of plasma volume in the circulation.

Arterial stiffness typically observed from arterial pulse wave velocity (PWV) evaluation can also be negatively affected by RE [9] and hydration status [16]. PWV is considered an independent predictor of coronary heart disease, stroke, and mortality [17], reduced arterial stiffness is typically perceived as beneficial because it indicates a more compliant artery conversely, increased arterial stiffness is one of the first signs of pathological changes in the arterial wall leading to an increased risk of cardiovascular events [18].

There have been numerous consensus guidelines proposing protocols to standardize the measurement of arterial stiffness/ PWV and thereby ensure high-quality research, nonetheless, no one up to date has considered the influence of plasma volume.

Figueroa et al. [9], pointed out a linear relationship between exercise intensity $\mathrm{x}$ PWV during and shortly after the end of a RE session. As the intensity of exercise increases, there is a concomitant increase in blood pressure and PWV. This is important because arterial stiffness increase is strongly associated with elevated sympathetic nerve modulation, cardiac workload and reduction in cardiac perfusion thus increasing the future risk of left ventricular hypertrophy and myocardial ischemia.

Regarding arterial stiffness and hydration, there are inconsistent findings. In a recent study from our group, water intake hindered arterial stiffness caused by high intensity RE [14]. Alternatively, demonstrated that mild dehydration (reduction of $2 \%$ of body mass) caused by passive heat, provoked a reduction in central PWV when compared to euhydration.

The contradictory results can be partially explained by the different nature of plasma volume reduction, as mentioned before, during a RE session there is an increase in blood pressure that would lead to PV reduction. On the other hand, during heat stress, vasodilation occurs in the periphery to increase blood flow to the skin in attempt to maximize heat loss. Overall, heat stress acts as an arterial vasodilator, much like nitrates, which reduces stiffness of the peripheral, but not central, arteries.

There is no agreement as to why PV reduction may affect arterial stiffness; however, Arnaoutis et al. [19] verified that in healthy young adults, dehydration reduced endothelial function, and reductions in endothelial function are strongly correlated with increased arterial stiffness. Furthermore, blood pressure also seems to influence the measurement of arterial stiffness; hypovolemia can acutely reduce blood pressure [12] and thereby reduce arterial stiffness.

Despite those contradictions, reduction of PV seems to play an important role as one of the mechanisms of arterial stiffness changes and as well as an intervening variable to cardiovascular response to RE.

\section{Conclusion}

Up to the present date several questions regarding hydration status and RE influence on arterial stiffness remains to be addressed. In that sense, Future investigations are necessary to elucidate the mechanisms and variables influencing this process. Also, it is desirable to develop strategies to hinder the increased autonomic modulation and arterial stiffness response to RE exercise minimizing the risk of cardiovascular events. We strongly suggest that future studies should standardize water intake and control hydration status before and during experimental sessions utilizing simple measures such as urine specific gravity and body weight.

\section{References}

1. Teixeira AL, Ramos PS, Marins JB, Ricardo DR (2015) The Role of Water Intake on Cardiac Vagal Reactivation after Upper-body Resistance Exercise. Int J Sports Med 36(3): 204-208.

2. AHA STATISTICAL UPDATE (2018) Heart Disease and Stroke Statistics2018 Update. A Report from the American Heart Association. Circulation 137: e67-e492. 
3. Colberg SR, Albright AL, Blissmer BJ, Braun B, Chasan-Taber L, et al (2010) Exercise and type 2 diabetes: American College of Sports Medicine and the American Diabetes Association: joint position statement. Exercise and type 2 diabetes. Med Sci Sports Exerc 42(12): 2282-2303.

4. Pescatello LS, Franklin BA, Fagard R, Farquhar WB, Kelley GA, et al (2004) American college of Sports Medicine position stand: exercise and hypertension. Med Sci Sports Exerc 36(3): 533-553.

5. Casonatto J, Goessler KF, Cornelissen VA, Cardoso JR, Polito MD (2016) The blood pressure-lowering effect of a single bout of resistance exercise: A systematic review and meta-analysis of randomised controlled trials. Eur J Prev Cardiol 23(16): 1700-1714.

6. Ferrario M, Moissl U, Garzotto F, Cruz DN, Clementi A, et al. (2014) Effects of fluid overload on heart rate variability in chronic kidney disease patients on hemodialysis. BMC Nephrol 15: 26.

7. Bush JA, Kraemer WJ, Mastro AM, Triplett-McBride NT, Volek JS, et al. (1999) Exercise and recovery responses of adrenal medullary neurohormones to heavy resistance exercise. Med Sci Sports Exerc 31(4): 554-559.

8. Rezk CC, Marrache RCB, Tinucci T, Mion D, Forjaz CL (2006) Postresistance exercise hypotension, hemodynamics, and heart rate variability: infuence of exercise intensity. Eur J Appl Physiol 98(1) 105-112.

9. Figueroa A, Okamoto T, Jaime SJ, Fahs CA (2019) Impact of highand low intensity resistance training on arterial stiffness and blood pressure in adults across the lifespan: a review. Pflugers Arch 471(3): 467-478.

10. Buchheit M, Rabbani A (2014) 30-15 Intermittent Fitness Test versus the Yo-Yo Intermittent Recovery Test Level 1: relationship and sensitivity to training. Int J Sports Physiol Perform 9(3): 522-524.
11. Chen CY, Bonham AC (2010) Postexercise hypotension: central mechanisms. Exerc Sport Sci Rev 38(3): 122-127.

12. Coble JP, Grobe JL, Johnson AK, Sigmund CD (2015) Mechanisms of brain renin angiotensin system- induced drinking and blood pressure: importance of the subfornical organ. Am J Physiol Regul Integr Comp Physiol 308(4): R238-R249.

13. Craig J (2006) What's to drink? Staying hydrated in the heat. Diabetes Self Manag 23(4): 6-8, 11-2, 14

14. Rodriguez D, Nakazato K, Naoki K, Alegretti G, Pontes Jr L, Figueira Jr A (2019) Water intake during resistance training affects arterial stiffiness in normotensive healthy adults. Med Sci in Sports Exer S662 51(5) Supplement.

15. Ahmadizad S, El-Sayed MS (2003) The effects of graded resistance exercise on platelet aggregation and activation. Med Sci Sports Exerc 35(6): 1026-1032.

16. Bia D, Galli C, Zocalo Y, Valtuille R, Wray S, et al. (2018) Central-ToPeripheral Arterial Stiffness Gradient in Hemodialyzed Patients Depends on the Location of the Upper-limb Vascular Access. Curr Hypertens Rev 14(2): 128-136.

17. Mattace-Raso FU, van der Cammen TJ, Hofman A, van Popele NM, Bos ML, et al. (2006) Arterial stiffness and risk of coronary heart disease and stroke: the Rotterdam Study. Circulation 113(5): 657-663.

18. Townsend RR, Wilkinson IB, Schiffrin EL, Avolio AP, Chirinos JA, et al. (2015) Recommendations for Improving and Standardizing Vascular Research on Arterial Stiffness: A Scientific Statement from the American Heart Association. American Heart Association Council on Hypertension. Hypertension 66(3): 698-722.

19. Arnaoutis G, Kavouras SA, Stratakis N, Likka M, Mitrakou A, et al. (2017) The effect of hypohydration on endothelial function in young healthy adults. Eur J Nutr 56(3): 1211-1217.

Your next submission with Juniper Publishers
will reach you the below assets
- Quality Editorial service
- Swift Peer Review
- Reprints availability
- E-prints Service
- Manuscript Podcast for convenient understanding
- Global attainment for your research
- Manuscript accessibility in different formats
( Pdf, E-pub, Full Text, Audio)
- Unceasing customer service
Track the below URL for one-step submission
https://juniperpublishers.com/online-submission.php

